\title{
La Fundación de la Orden de Servitas. Una estampa del escultor Fernando Ortiz en la Colección Antonio Rodríguez-Moñino-María Brey
}

\author{
Federico Castellón Serrano \\ Universidad de Málaga \\ federicocastellon@gmail.com
}

Un importante fondo de la Real Academia Española de la Lengua es la colección Antonio Rodríguez-Moñino-María Brey ${ }^{1}$.

Rodríguez-Moñino, nacido en 1910, fue un intelectual que despuntó muy pronto por sus estudios literarios, logrando una cátedra de instituto en 1935. Poco después su acreditada solvencia y numerosas investigaciones como bibliófilo y filólogo, propiciarían su nombramiento como experto de la Junta de Protección del Tesoro Artístico de la República. Lamentablemente, tras la Guerra Civil fue despojado de su cátedra tras ser sometido a un expediente de depuración que tardaría veintiocho años en resolverse. Sin embargo, Rodríguez-Moñino fue siempre objeto de una gran consideración tanto fuera ${ }^{2}$ como dentro del país, contando con el reconocimiento y el apoyo de Lázaro Galdiano y de buena parte de la Real Academia Española, que lo nombró Académico Correspondiente en 1952, e intentó hacerlo de número en 1960, a propuesta de Dámaso Alonso, José María de Cossío y Camilo José Cela, aunque entonces fue vetado por el Gobierno de Franco, y su ingreso no se produjo hasta 1966 [1].

María Brey estudió Filosofía y Letras en Madrid, ingresando en 1931 en el Cuerpo Superior Facultativo de Archiveros, Bibliotecarios y Arqueólogos, trabajando como bibliotecaria en la Universidad de Santiago de Compostela y en la de la Presidencia del Consejo de Ministros. Fue depurada en 1940 y trasladada a Huelva, retornando a Madrid en 1943, al concedérsele interinamente un puesto de trabajo en la Biblioteca de las Cortes. Su vida intelectual fue muy intensa tanto hacia la biblioteconomía, como a la traducción o la dirección de colecciones literarias.

A lo largo de su vida, el matrimonio Antonio Rodríguez-Moñino y María Brey formaron un valioso y cuantioso

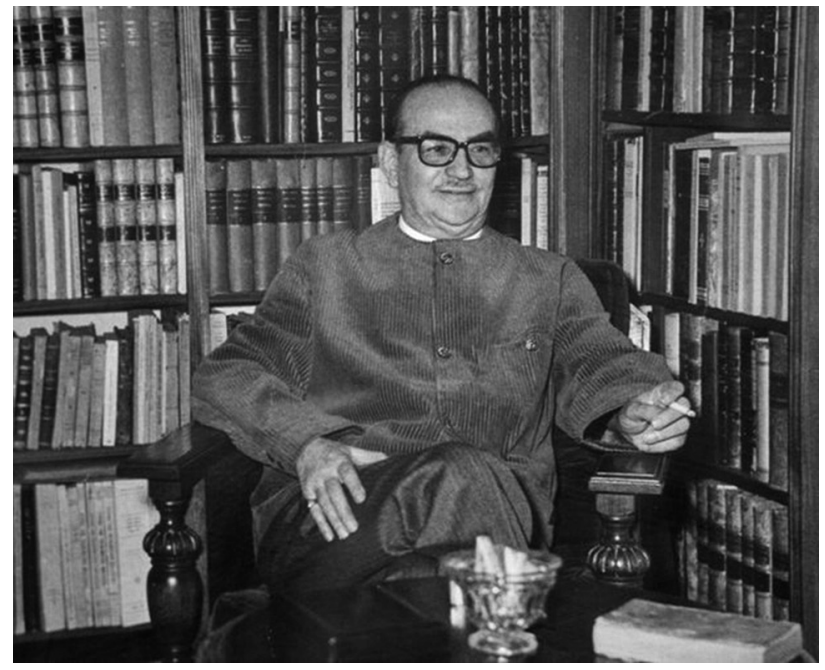

1. Antonio Rodríguez-Moñino. Real Academia Española

fondo compuesto por más de 15.000 volúmenes, además de dibujos, manuscritos y grabados. En palabras de Lázaro Carreter «no se preciaba de acumular papel, sino de que éste fuera significativo para la historia de la literatura y, muchas veces, para la del arte» (1995: 16). Tras el fallecimiento de su marido en 1970, el legado quedó al cuidado de María Brey que se encargó de su catalogación. Por disposición testamentaria, la ilustre bibliotecaria donó la colección a la Real Academia Española, en la que se depositó tras su muerte en 1995.

El lote correspondiente a obra gráfica de la Colección Rodríguez-Moñino-Brey se compone nada menos que de 3.737 estampas, que vinieron a engrosar los fondos de la Real Academia, además de 147 matrices de los siglos XVIII y $X I X$, que fueron depositadas por la RAE en la Calcografía Nacional de la Real Academia de Bellas Artes de San Fernan- 


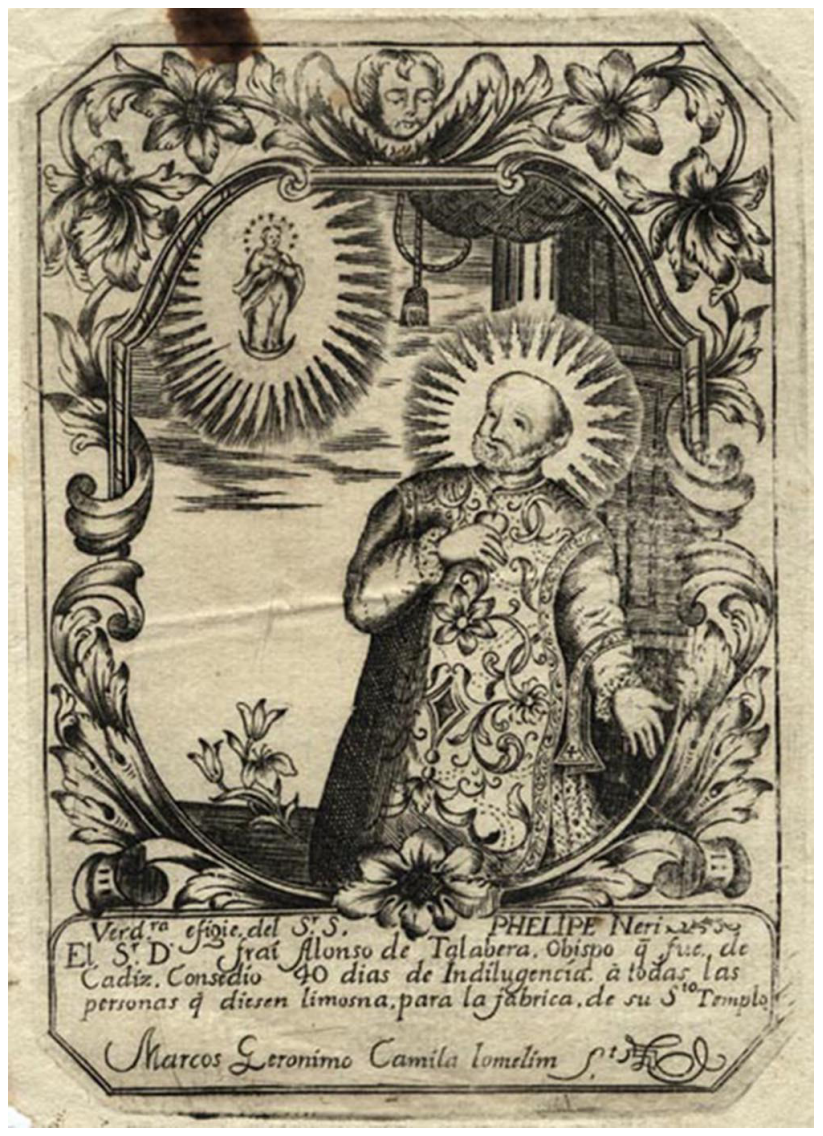

2. Verdadera efigie del Sr. S. Felipe Neri. Marcos Jerónimo Camilo Lomelín. Grabado calcográfico, c. 1725. Real Academia Española

do, dadas las mejores condiciones e instalaciones de esta institución para la conservación de las láminas de cobre.

En el fondo de estampas ubicadas en la RAE, además de litografías decimonónicas de diversas vistas malagueñas, realizadas por George Vivian o David Roberts, o del Puente Nuevo de Ronda, de John Frederick Lewis, nos encontramos con varias obras muy significativas para el arte del grabado en Málaga.

Siguiendo un orden cronológico, la primera de las estampas es una Anunciación realizada en el primer tercio del siglo XVIII en talla dulce, atribuida a Porras, grabador del que ya conocíamos una obra firmada en Málaga hacia 1731, La Venerable Madre Sor María Negro, destinada a ilustrar un libro dedicado a glosar la vida y milagros de la religiosa (Castellón, 2013: 54-56). A esta misma época, o quizá algo anterior pertenece una estampa de San Felipe Neri, para fo- mentar limosnas para la edificación de un templo dedicado al santo [2]. El grabado está firmado por el calcógrafo malagueño Marcos Jerónimo Camilo Lomelin, del que se conocían algunas obras firmadas en Madrid y Barcelona entre 1724 y 1730 (Carrete, s.a.). Al primer tercio del siglo XIX pertenece el precioso grabado de la Virgen de las Angustias del trascoro de la catedral de Málaga, dibujada por Guerrero y grabada por Luis Fernández Nosseret, calcógrafo que había sido discípulo de Manuel Salvador Carmona. Curiosamente, esta estampa no reproduce la imagen neoclásica de la catedral malagueña, obra de los hermanos Pissani, sino a la Virgen de las Angustias de Pozuelo de Alarcón, realizada por Juan Adán. Esta atribución aparecía escrita como tal en otra estampa de 1814, dibujada por Cosme de Acuña y grabada por Blas Ametller, en cuya leyenda rezaba textualmente: «Estampa de nuestra Señora de las Angustias en pliego de marca mayor, como se venera en el trascoro de la santa iglesia catedral de Málaga [...] de la célebre escultura executada por don Juan Adán ${ }^{3}$.

Por último, en la colección de estampas del legado Rodríguez-Moñino-Brey encontramos también tres grabados de comienzos del siglo XX del pintor malagueño, Fernando Labrada Martín, que además fue un excelente grabador, con especial dominio del aguafuerte.

El fondo localizado en la Real Academia de la Lengua, ha sido digitalizado y puede consultarse con facilidad en la página web de dicha institución. No ocurre igual con las matrices de cobre depositadas en la Real Academia de Bellas Artes de San Fernando.

En el catálogo de la calcografía, correspondiente a la colección, aparecía un lote de imágenes devocionales malagueñas, entre las que se encontraban tres Vírgenes de los Dolores: una anónima, otra firmada por Francisco Torres, y otra de Lorenzo Sánchez Mansilla, la Virgen del Carmen de Antequera, grabada por Pastrana, y un escudo heráldico de un caballero de Santiago, grabado por Francisco de la Torre. Sin embargo el acceso a estas planchas, sujeto a unas estrictas medidas de conservación, mantienen prácticamente vetado su análisis directo por parte de los interesados.

Tras largas gestiones con la Academia de San Fernando y tras conseguir la autorización de su comisión de calcografía, pudimos encargar la reproducción fotográfica de aquellas añejas planchas, tan celosamente custodiadas y afortunadamente conservadas. La investigación produjo ex- 
celentes resultados ya que, por una parte, la plancha de la Dolorosa del granadino Francisco Torres, era la estampa que conocíamos de la Virgen de Servitas de Málaga, hasta ahora anónima, ya que el único ejemplar conservado en Málaga, incluido en las Memorias de la Congregación de San Felipe Neri, del padre Juan Vicente Zamora, tiene recortada la firma del grabador [3].

Por otro lado, en raras ocasiones se encuentra la lámina de un grabado ya conocido, siendo este el caso de la estampa de la Virgen del Carmen de Antequera, grabada por Pastrana en aquella localidad en 1766, que se conserva el Archivo Municipal de Antequera.

La lámina de la Virgen de los Dolores que se encuentra sin firma, al presentar sus bordes recortados, es un excelente trabajo de dibujo y grabado, aunque no encontramos en ella otra conexión con Málaga que la que ofrece el propio catálogo de la colección, dato que quizá correspondiera al lugar de su adquisición. De indudable interés es el grabado heráldico de Francisco de la Torre, de un caballero de la Orden de Santiago, ya que viene a completar la obra conocida del calcógrafo malagueño de finales del siglo XVIII (CasteIlón, 2013 y Castellón, 2018). La leyenda «Amarae vitae dulcis exitus» en uno de sus cuarteles, fue utilizada por la familia nobiliaria Vasco y Vargas de Ronda, pudiendo corresponder este blasón a alguno de sus miembros.

Pero la mayor sorpresa nos la ofreció la plancha de la Virgen de los Dolores grabada por Lorenzo Sánchez Mansilla en 1767 [4a]. La lámina no está descrita en su totalidad en el catálogo de la calcografía, habiéndose omitido el nombre de su inventor, que sin embargo sí consta en la plancha, el gran escultor de la Málaga del XVIII Fernando Ortiz, representando esta lámina en cobre la segunda incursión conocida del imaginero en el arte del grabado, tras la Aparición de la Virgen de la Victoria a San Francisco de Paula, dibujada en 1757 y que llevó al cobre el calcógrafo valenciano Manuel Monfort.

Como reza en su leyenda, fue encargada por un presbítero de la Congregación de Málaga en 1767, encargo que viene a sumarse a una importante producción artística realizada por Ortiz para los filipenses malagueños, como la imagen de la Virgen de Servitas, donada por el padre Rojas a la Orden Tercera, un San Juan Nepomuceno y un San José con el Niño (destruidos en los sucesos de mayo de 1931) y un San Antonio Abad, que Ortiz ofrendó tras una promesa, para la er-

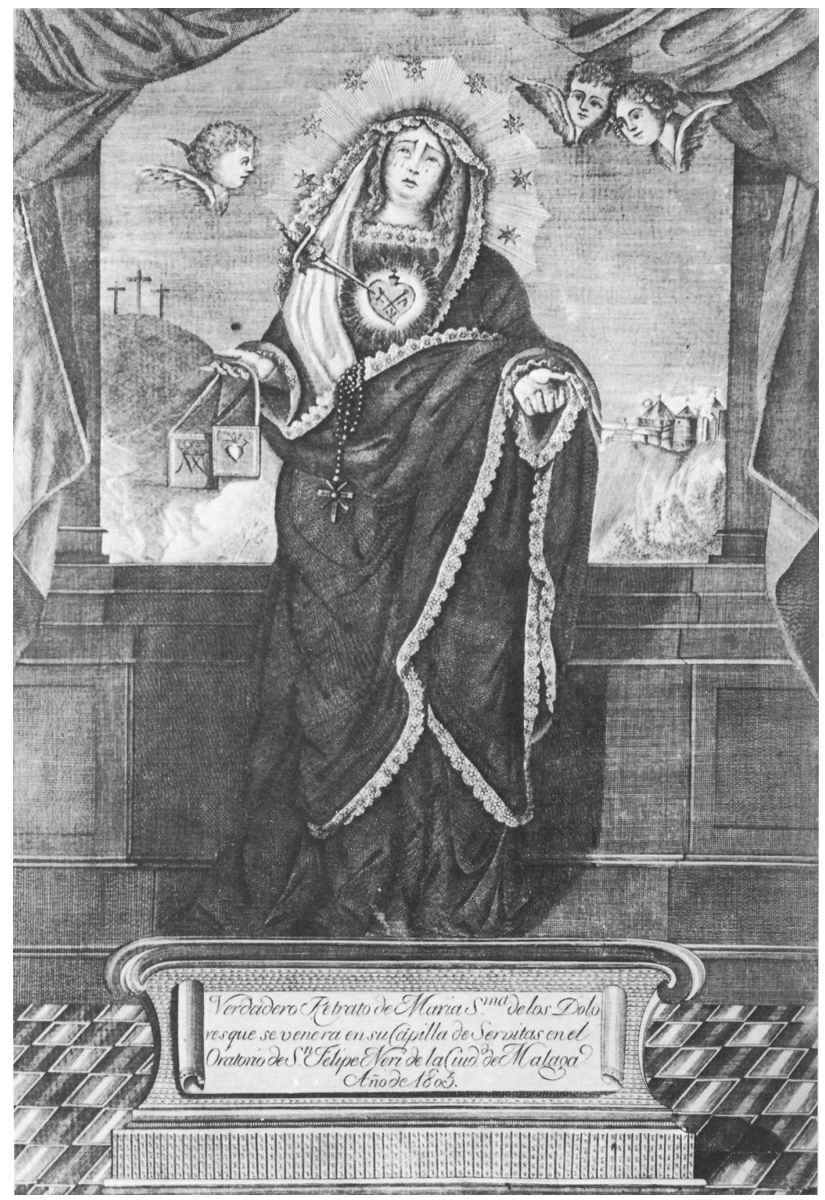

3. Virgen de los Dolores de la VOT de Servitas de Málaga. Francisco Torres, grabado, 1803

mita que construyeron los filipenses en el Monte de San Antón, y que hoy se encuentra expuesto en el Museo de Málaga.

Por otra parte, los filipenses malagueños no fueron ajenos al poder propagandístico y devocional del grabado, como demuestra la conservación de varias estampas relacionadas con la Orden o alguno de sus miembros más eminentes. Del padre Cristóbal de Rojas realizará un retrato el grabador Tomás Prieto en 1757. Los devotos de San Felipe Neri de Colmenar encargarán un retrato del santo en 1784 al grabador malagueño Francisco de la Torre, y en 1803 se graba el ya mencionado «verdadero retrato» de la Virgen de los Dolores de Servitas, del que ahora conocemos por su plancha que es obra del granadino Francisco Torres.

Con respecto al calcógrafo de la estampa que nos ocupa, el madrileño Lorenzo Sánchez Mansilla, aunque no 


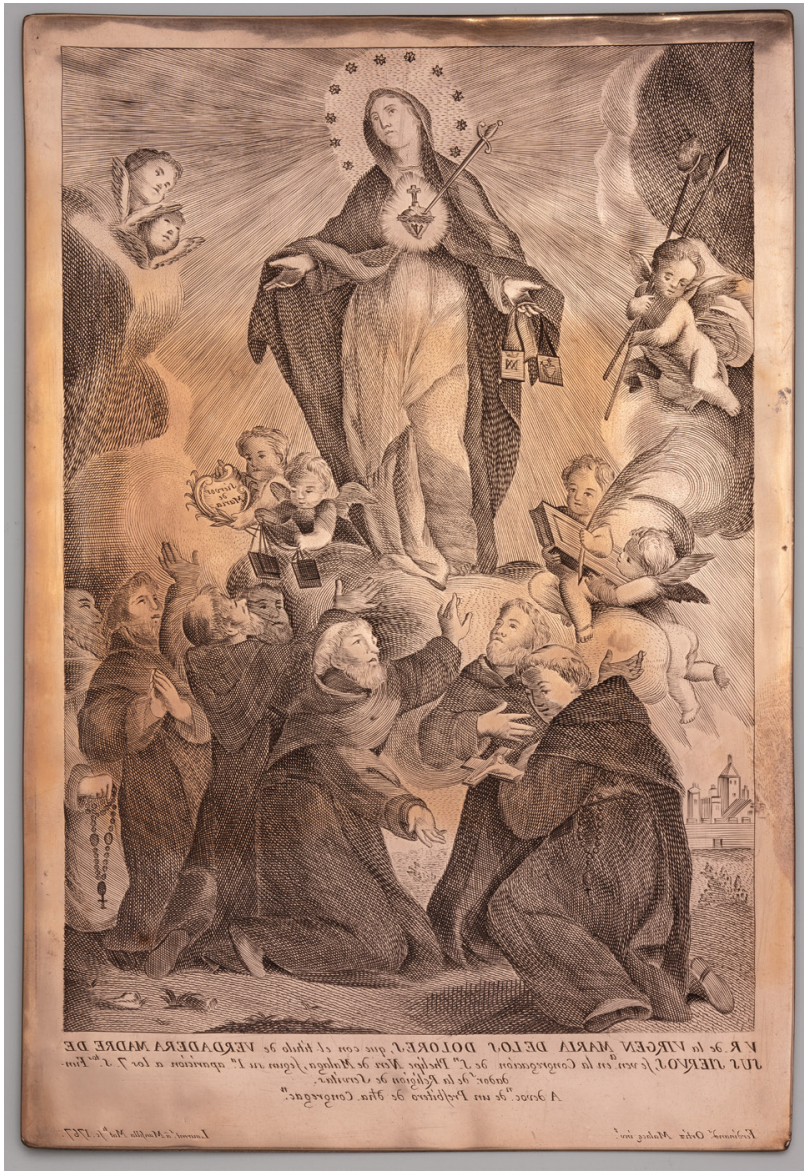

4a. Lámina en cobre. La Fundación de la Orden de Servitas. Fernando Ortiz, dibujo. Lorenzo Sánchez Mansilla, grabado, 1767. Calcografía Nacional. Real Academia de Bellas Artes de San Fernando. Madrid

alcanza la calidad técnica de las grandes figuras del grabado de su época, realizó una variada obra a finales del siglo XVIII: estampa religiosa, diversos retratos de nobles, miembros de la familia de Carlos IV y del propio monarca; aunque destacará especialmente como grabador de letra, interviniendo en la realización de varios libros de caligrafía y paleografía. Un dato oscuro de su biografía fue la falsificación del sello de un título de medicina, por la que recibió condena a 6 años de presidio en 1769, aunque poco después sería indultado (Campos, 1999: 182). Para Málaga realizó también el escudo del Colegio de Abogados en 1776.

El grabado de los Servitas malagueños representa la entrega de los escapularios y de la regla de San Agustín a los Siete Santos Fundadores. Este grupo de devotos de la

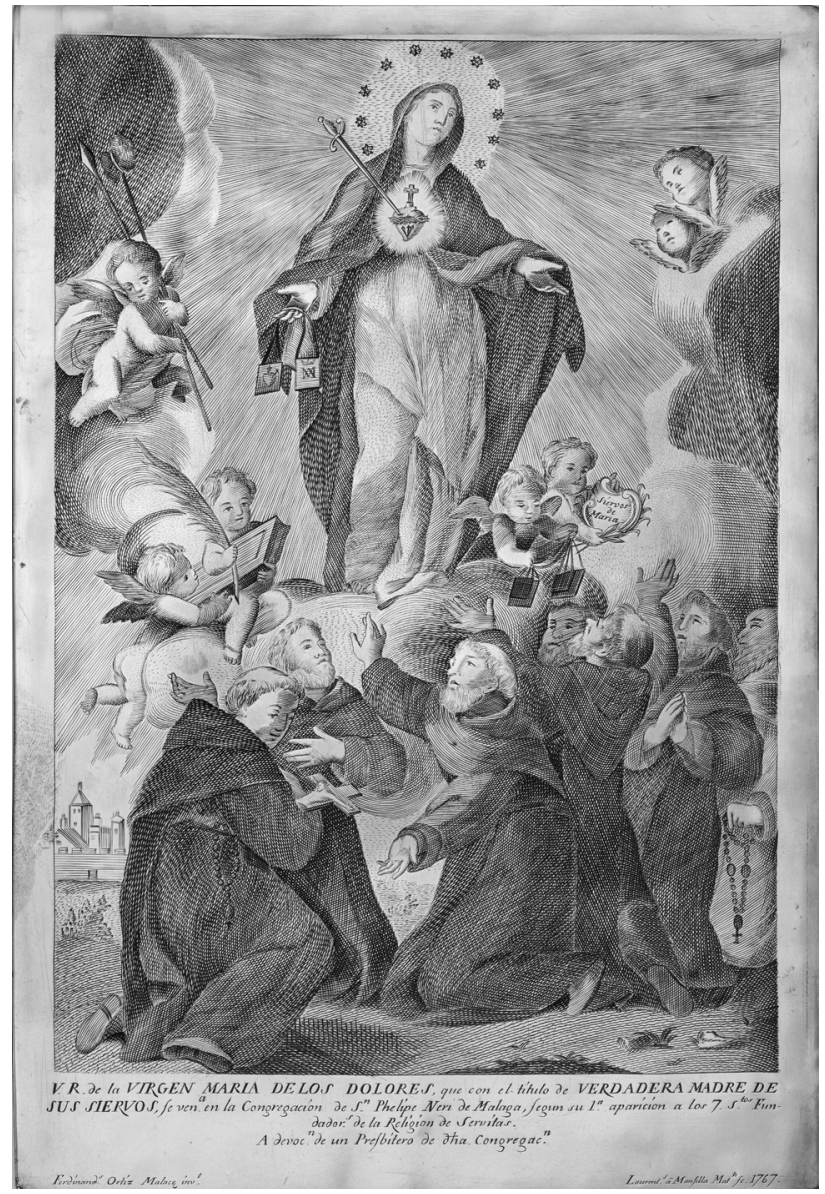

4b. Positivo de la lámina obtenido por procedimiento digital
Virgen María, formado por comerciantes florentinos, decidió el día de la Asunción de 1233 fundar la orden, abandonando la vida mundana y retirándose a la vida contemplativa en el Monte Sinario. La escena fue reproducida a lo largo del tiempo por varios autores, siendo la versión más conocida la realizada por el pintor romano Agostino Masucci en 1727. En este caso la Virgen entrega a los fundadores los hábitos monásticos de su nueva vida en religión.

Aunque la leyenda del grabado dice textualmente «V.R. de la Virgen María de los Dolores, que con el título de Verdadera Madre de sus siervos, se venera en la Congregación de San Felipe Neri de Málaga», la composición de Ortiz no reproduce la imagen de la Dolorosa de Servitas que realizó él mismo. En todo caso guarda algunas coincidencias 
con la Dolorosa de busto y talla completa -como la cabeza levantada hacia arriba, cubierta por el manto, y los brazos abiertos- que fue donada por el Conde de Buenavista para favorecer el establecimiento de la Orden Tercera, que él mismo había encargado a los filipenses ${ }^{4}$.

La estampa [4b], que como vemos se dedica principalmente a relatar la fundación de la Orden y no como «verdadero retrato» de la imagen, desarrolla la escena en dos niveles, siguiendo el recurso del rompimiento de gloria. En el plano superior, o espiritual, se representa a la Virgen cubierta por un manto y con halo de estrellas, en su pecho se representa el Sagrado Corazón atravesado por una daga larga, presentando las manos abiertas, sujetando con la derecha el escapulario.
El rostro presenta las cejas arqueadas, a diferencia de las apuntadas de la Dolorosa de Ortiz. Junto a la Virgen unos ángeles sujetan la lanza y la esponja, mientras que los situados más abajo entregan la Regla, el escapulario y una cartela con el título de la nueva Orden: «Siervos de María». En el plano inferior o terrenal se disponen los Siete Fundadores, presentados con mayor detalle los situados en primer plano, quedando el retrato esbozado en los más alejados. El pequeño núcleo arquitectónico florentino, se reproduce con unas simples líneas rectas y oblicuas.

En general, el trabajo de grabado es algo pobre, especialmente en el tosco tratamiento de las tramas a buril, muy lejano al que realizó Monfort en la estampa ya mencionada de la Virgen de la Victoria.

\section{Notas}

1 Extraemos estas notas biográficas de Lázaro (1995).

2 Fue nombrado miembro numerario de la Hispanic Society de Nueva York, doctor honoris causa por la Universidad de Burdeos, y profesor de la Universidad de Berkeley.

3 Carrete Parrondo localiza el anuncio de venta de este grabado en la Gaceta de Madrid de 19 de julio de 1814. Carrete (2015).

4 Sobre la coexistencia de ambas imágenes como titulares de la Orden Tercera de Servitas ver Romero (2017: 183-184).

\section{Bibliografía}

CAMPOS, María Soledad (1999), El Real Tribunal del protomedicato castellano, siglos XIV-XIX, Universidad de Castilla La Mancha, Cuenca. CARRETE PARRONDO, Juan (s.a.), «Diccionario de grabadores y litógrafos que trabajaron en España. Siglos XV a XIX». Obra en curso de realización. En <https://sites.google.com/site/arteprocomun/diccionario-de-grabadores-y-litografos-que-trabajaron-en-espana-siglos-xv-xix-h---z> (fecha de consulta: 09-11-2018).

- (2015), «Las estampas en la prensa madrileña de 1814 a 1819». En <https://sites.google.com/site/arteprocomun/estampas-en-la-prensa-madrilena-de-1814-a-1819> (fecha de consulta: 15-08-2108).

CASTELLÓN, Federico (2013), El grabado calcográfico en la Málaga Moderna. Francisco de la Torre, grabador y maestro de dibujo, Centro de Ediciones de la Diputación Provincial de Málaga, Málaga.

- (2018), La Estampa llustrada en Málaga. La obra del grabador Francisco de la Torre (1776-1800), Ayuntamiento de Málaga, Málaga. HEREDIA, Víctor (2002), Gaona. De Congregación de San Felipe Neri a Instituto de Enseñanza Secundaria. (1739-2002), Ágora, Málaga. LÁZARO CARRETER, Fernando (1995), «El legado Rodríguez Moñino-María Brey», Abc Cultural, 6 de octubre, pp. 16-17.

REAL ACADEMIA DE BELLAS ARTES DE SAN FERNANDO. CALCOGRAFÍA NACIONAL, "Catálogo de láminas». En <http://www.realacademiabellasartessanfernando.com/es/calcografia-nacional/colecciones/laminas>.

REAL ACADEMIA ESPAÑOLA (2006), «Catálogo de la Colección Rodríguez Moñino. Subcatálogo de Estampas». En <http://cronos.rae.es/ Absys/abwebp.exe/X5117/ID24520/G5>.

ROMERO TORRES, José Luis (2017), Fernando Ortiz. Un escultor malagueño del siglo XVIII, Patronato de Arte. Amigos de los Museos de Osuna, Osuna (Sevilla).

ZAMORA, Juan Vicente y otros (siglo XVIII), Memorias de la Congregación de San Felipe Neri de Málaga, Málaga. 